\title{
Structure and Catalytic Properties of Co-Fe Systems in the Reaction of $\mathrm{CO}_{2}$ Methanation
}

\author{
M. Zhludenko ${ }^{a}$, A. Dyachenko ${ }^{a}, \mathrm{O}$ Bieda $^{a, *}$, S. Gaidai $^{a}$, M. Filonenko $^{b}$ \\ AND O. ISCHENKO ${ }^{a}$ \\ ${ }^{a}$ Taras Shevchenko National University of Kyiv, 64/13 Volodymyrs'ka Str, Kyiv, 01601, Ukraine \\ ${ }^{b}$ National Pedagogical Dragomanov University, 9 Pirogova Str., Kyiv, 01601, Ukraine
}

\begin{abstract}
The properties of $\mathrm{Fe}-\mathrm{Co}$ catalysts in the reaction of $\mathrm{CO}_{2}$ hydrogenation were investigated. Samples with high cobalt concentrations have shown higher activity. Morphology of the obtained catalysts was observed by using scanning electron microscopy and the elemental composition of surface of the catalysts was determined by scanning electron microscopy-energy dispersive X-ray method. Energy dispersive X-ray analysis showed that metal distribution is not homogeneous with various metal ratio in selected points of the surface for the Fe-rich less active samples, whereas for the Co-rich samples with higher activity metals are homogeneously distributed, which is possibly connected to the formation of single phase.
\end{abstract}

DOI: 10.12693/APhysPolA.133.1084

PACS/topics: 82.30.Hk, 82.30.-b, 82.20.-w

\section{Introduction}

State of the environment and the greenhouse problem are still ones of the most pronounced ecological problems. The increase in $\mathrm{CO}_{2}$ emissions leads, in particular, to the negative climatic changes.

The $\mathrm{CO}_{2}$ hydrogenation process (the Sabatier reaction) is one of the effective methods of removal of $\mathrm{CO}_{2}$, allowing not only to utilize its excess but to convert it into light hydrocarbons, opening the way to the new sources of fuel $[1,2]$.

One of the most perspective ways to solve the mentioned tasks is so-called power-to-gas technology. The concept is to use the excess of energy to split water into $\mathrm{H}_{2}$ and $\mathrm{O}_{2}$, with further conversion of hydrogen and carbon dioxide into methane. Thus, the renewable energy can be stored in the already existing network of the natural gas, utilizing its great volumes. Moreover, natural gas is a convenient fuel that is already widely used in different aspects of human life, and does not show the security problems connected with use of gaseous hydrogen [3, 4].

$\mathrm{CO}_{2}$ hydrogenation depending on the conditions and the type of catalyst used gives a wide spectrum of products, from $\mathrm{CO}$ and $\mathrm{CH}_{4}$ to ethylene and higher hydrocarbons. Literature data are present on studies of metallic catalysts based on transition metals $(\mathrm{Ni}, \mathrm{Co}, \mathrm{Fe}, \mathrm{Mn}, \mathrm{Cu}$, $\mathrm{Zn}$ etc.) $[5-8]$ as well as on the noble ones ( $\mathrm{Pt}, \mathrm{Pd}, \mathrm{Ru}$, Rh etc.) $[9,10]$. From the economical point of view, use of non-noble metals is more proficient [11, 12].

No common point of view on the mechanism of the Sabatier reaction exists at the time. The significant part of potential combinations of active phase, promoter and

*corresponding author; e-mail: a_byeda@chem.knu.ua support remains not examined yet. It is desired to create thermally and mechanically stable catalysts that possess highly specific surface. Thus, it can be stated that the search of cheap catalysts compliant with the abovementioned is an actual task.

\section{Experimental}

A series of metallic samples based on Fe and Co with different Co:Fe ratio was obtained as below. The calculated amounts of metals were dissolved in the concentrated nitric acid, the solution was cooled to room temperature (r.t.) and hydroxides were precipitated by excess of $\mathrm{NH}_{3}$ solution. The precipitate after the evaporation was dried at $180^{\circ} \mathrm{C}$ and pre-reduced in flow of $50 \% \mathrm{H}_{2}$ in helium for $2 \mathrm{~h}$ at $350^{\circ} \mathrm{C}$.

The catalytic activity of the samples was studied in a fixed bed reactor in flow of $2 \% \mathrm{CO}_{2}+55 \% \mathrm{H}_{2}$ mixture (balanced with $\mathrm{He}$ ), at total flow of $100 \mathrm{~cm}^{3} / \mathrm{min}$ and sample mass of $1 \mathrm{~g}$. The reactor with inner diameter of $8 \mathrm{~mm}$ contained a $1 \mathrm{~mm}$ glass tube with a thermocouple inside, put in the catalyst bed. The pre-treatment of sample in the reaction mixture was made by gradual increase of the catalyst temperature to $450^{\circ} \mathrm{C}$ over $3 \mathrm{~h}$. The exiting gaseous mixture was analyzed by gas chromatograph with a thermal conductivity detector (Shimadzu GC-2014, $1 \mathrm{~m}$ length packed column, molecular sieves $5 \mathrm{~A})$.

XRD studies of the samples were performed on a diffractometer MiniFlex 600 (Rigaku, Japan) with Co $K_{\alpha}$ radiation $(\lambda=1.7903 \AA)$. The morphology of samples and the chemical analysis were studied on the Tescan Mira 3 LMU scanning electron microscope (SEM) equipped with energy-dispersive X-ray (EDX) detector (Oxford INCA). The specific surface was assessed by adsorption of Ar at $77 \mathrm{~K}$. 


\section{Results and discussion}

The dependence of catalytic activity on the composition of the sample is shown in Fig. 1. The temperature of $300{ }^{\circ} \mathrm{C}$ was taken for the ease of the comparison as at this temperature the most active sample (93\% Co, $7 \%$ Fe) has reached $100 \%$ methane yield.

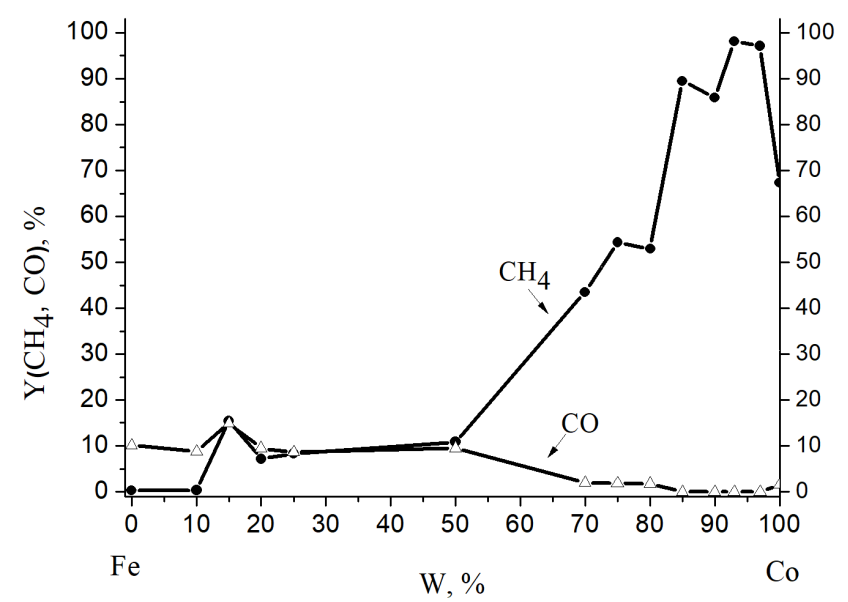

Fig. 1. Yield of reaction products at $300^{\circ} \mathrm{C}$ versus composition of the catalyst.

The data signify that the most active samples are in the region of high Co content. The activity increases rapidly with Co content when it exceeds $50 \%$. This can be explained by the fact that according to the phase diagram of Co-Fe system [13] an area of heterogeneity exists in this region of Co concentrations. A diffusionless transition from $\gamma+\alpha$ phases to $\varepsilon$ phase occurs in the solid solutions, and the transition temperature decreases down to r.t. for $91-93 \%$ of $\mathrm{Co}(\gamma-$ face-centered cubic $\mathrm{Co}-$ Fe solution, $\alpha$ - normal body-centered cubic iron, $\varepsilon$ normal hexagonal Co). Hence, the most active samples are expected to contain $\gamma$ phase only. It should be mentioned that $\mathrm{CO}$, which is a byproduct, is present for the samples with high Fe content but completely absent for the samples with high Co content $(>70 \%)$.

The characteristic catalytic curves (product yields versus temperature) are shown in Fig. 2 for the active $\left(\mathrm{Co}_{3} \mathrm{Fe}_{7}\right)$ and the inactive $\left(\mathrm{Co}_{14} \mathrm{Fe}_{86}\right)$ samples.

The active sample shows the start of reaction at $150^{\circ} \mathrm{C}$ and the total conversion to methane at $300^{\circ} \mathrm{C}$, which is a remarkable result for this type of catalysts in comparison to literature data [14]. The total absence of CO co-product is noteworthy for this sample. For the inactive one, the reaction starts at around $200^{\circ} \mathrm{C}$, the highest methane yield achieved is only $48 \%$ at $350{ }^{\circ} \mathrm{C}$ and $10 \%$ of $\mathrm{CO}$ is present in the reaction mixture.

For the active catalyst (Fig. 3a,b) the more defective structure in comparison to the inactive one (Fig. 3c,d) is clearly seen in the micrometer-range magnification. In the $\mathrm{nm}$ range a close examination shows the agglomerates in the active sample (ca. $80-100 \mathrm{~nm})$ and for the
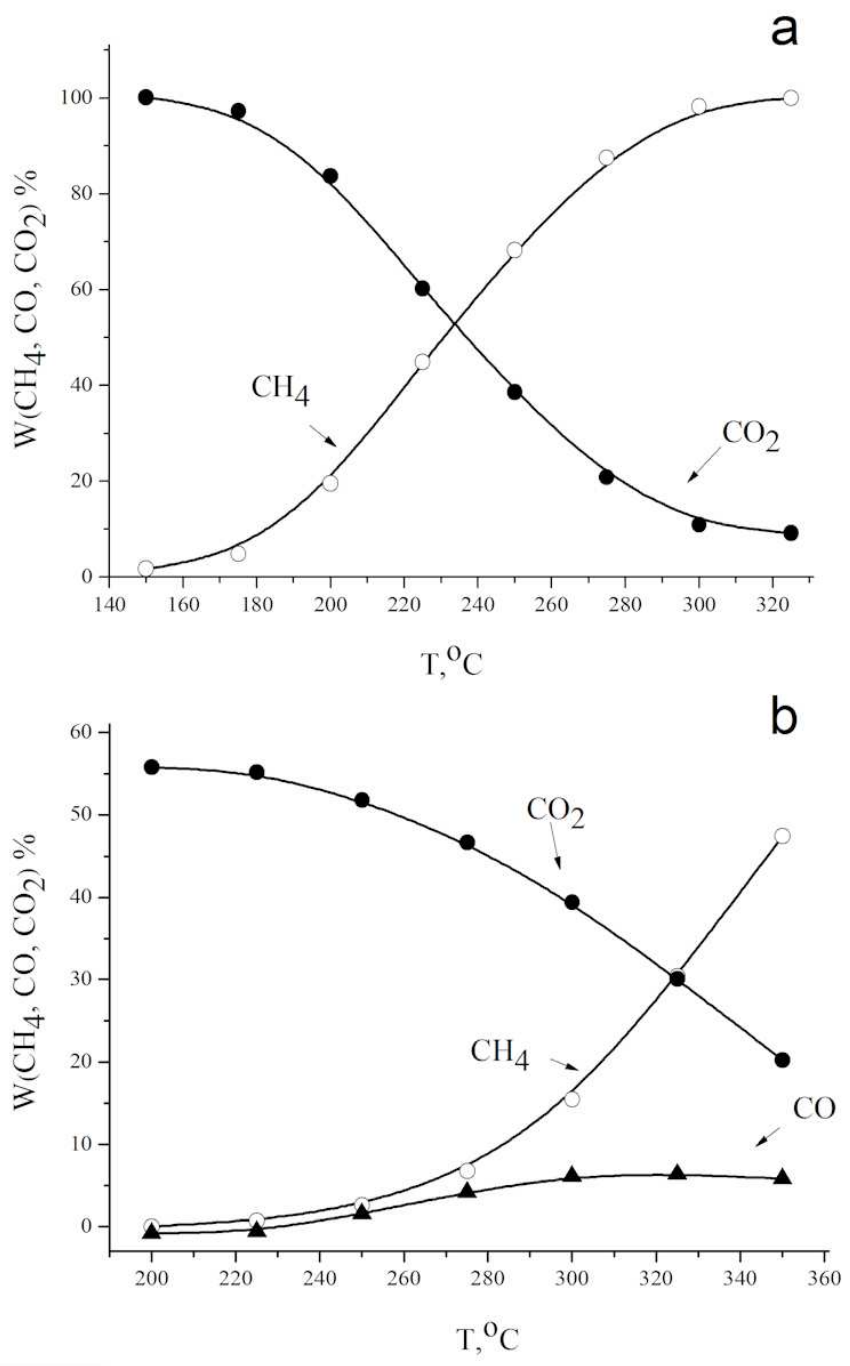

Fig. 2. Temperature dependences of $\mathrm{CH}_{4}$ and $\mathrm{CO}$ yields for $\mathrm{Co}_{93} \mathrm{Fe}_{7}$ (a) and $\mathrm{Co}_{14} \mathrm{Fe}_{86}$ (b).

inactive one the big agglomerates presumably resulted from sintering are observed, but for $\mathrm{Co}_{93} \mathrm{Fe}_{7}$ the particle size is about $40 \mathrm{~nm}$ and for $\mathrm{Co}_{14} \mathrm{Fe}_{86}$ about $80 \mathrm{~nm}$, the surface layer being much more defective for the former. The specific surface for all of the samples studied was about $18 \mathrm{~m}^{2} / \mathrm{g}$, indicating no notable difference in the accessible surface.

The EDX data show that for the active sample the metal ratio found in different regions is effectively the same and equals to the one given by synthesis (Table I). Instead, a strictly uneven distribution of $\mathrm{Co}$ and $\mathrm{Fe}$ is revealed in the inactive one.

The macroscopic structure of the samples is also different. $\mathrm{Co}_{93} \mathrm{Fe}_{7}$ shows the several $\mu$ m-sized aggregates with a porous surface, while $\mathrm{Co}_{14} \mathrm{Fe}_{86}$ shows the big aggregates in 10-50 $\mu \mathrm{m}$ range having the smooth surface. Size of the pores in the former is below $100 \mathrm{~nm}$, indicating the presence of both micro- and mesopores. For 

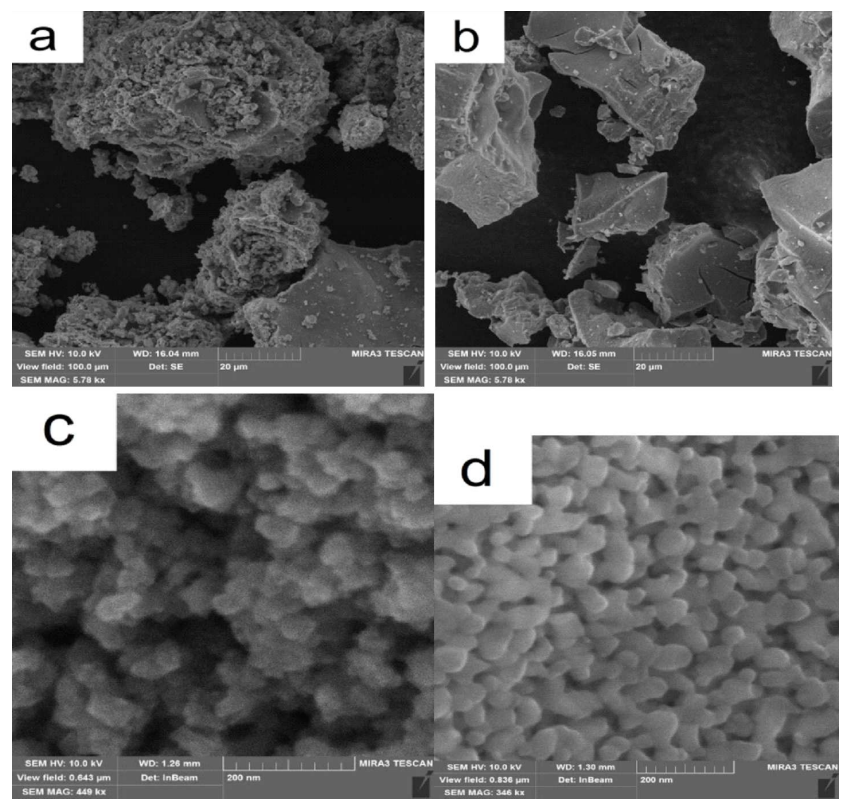

Fig. 3. Micrographs of $\mathrm{Co}_{93} \mathrm{Fe}_{7}$ sample ((a) $20 \mu \mathrm{m}$, (c) $200 \mathrm{~nm}$ ) and $\mathrm{Co}_{14} \mathrm{Fe}_{86}$ sample ((b) $20 \mu \mathrm{m}$, (d) $200 \mathrm{~nm}$ ).

SEM-EDX data for $\mathrm{Co}_{93} \mathrm{Fe}_{7}$

TABLE I

\begin{tabular}{c|c|c|c|c|c}
\hline \hline \multirow{2}{*}{ Region \# } & \multicolumn{3}{|c|}{ Content [at.\%] } & \multicolumn{2}{c}{ Fe:Co ratio } \\
\cline { 2 - 5 } & Fe & Co & O & by analysis & by synthesis \\
\hline 1 & 5.25 & 70.37 & 24.38 & $6.95: 93.05$ & \multirow{2}{*}{$7: 93$} \\
\hline 2 & 7.55 & 89.79 & 2.66 & $7.76: 92.24$ & \multirow{2}{*}{} \\
\hline 3 & 9.20 & 84.40 & 6.40 & $9.83: 90.17$ & \\
\hline 4 & 6.50 & 79.79 & 13.71 & $7.53: 92.47$ & \multicolumn{1}{|c}{}
\end{tabular}

$\mathrm{Co}_{14} \mathrm{Fe}_{86}$ one can mention a dense structure consisting of 70-80 nm spheroidal particles which are sintered in a thick layer. The elemental composition (see Table II) for this sample shows the inequality of metal ratios in different points to be of as high as $50 \%$.

$\mathrm{XRD}$ analysis of $\mathrm{Co}_{93} \mathrm{Fe}_{7}$ before the reduction in the reaction mixture showed only a $\mathrm{Co}_{3} \mathrm{O}_{4}$ phase. However, after catalytic test the diffraction pattern of the reduced sample (Fig. 4a) shows both cubic and hexagonal (the latter with low intensity and broadening of the reflexes) metallic cobalt and $\mathrm{CoO}$ oxide phase, the oxide presumably being a result of exposition to air after the catalytic test.

SEM-EDX data for $\mathrm{Co}_{14} \mathrm{Fe}_{86}$

TABLE II

\begin{tabular}{|c|c|c|c|c|c|}
\hline \multirow{2}{*}{ Region \# } & \multicolumn{3}{|c|}{ Content [at.\%] } & \multicolumn{2}{|c|}{ Fe:Co ratio } \\
\hline & $\mathrm{Fe}$ & Co & $\mathrm{O}$ & by analysis & by synthesis \\
\hline 1 & 56.41 & 33.93 & 9.30 & $62.44: 37.56$ & \multirow{4}{*}{$86: 14$} \\
\hline 2 & 81.46 & 6.04 & 12.50 & 93.10:6.90 & \\
\hline 3 & 69.00 & 11.06 & 19.94 & $86.19: 13.81$ & \\
\hline 4 & 67.35 & 10.80 & 19.46 & 66.59:33.41 & \\
\hline
\end{tabular}

Only iron oxides $\mathrm{Fe}_{2} \mathrm{O}_{3}$ and $\mathrm{Fe}_{3} \mathrm{O}_{4}$ are present in the pattern of the untreated, freshly synthesized $\mathrm{Fe}_{86} \mathrm{Co}_{14}$ sample. After the catalytic tests metallic $\alpha$-Fe and the residual $(\mathrm{Fe}, \mathrm{Co})_{3} \mathrm{O}_{4}$ are present (Fig. 4b).
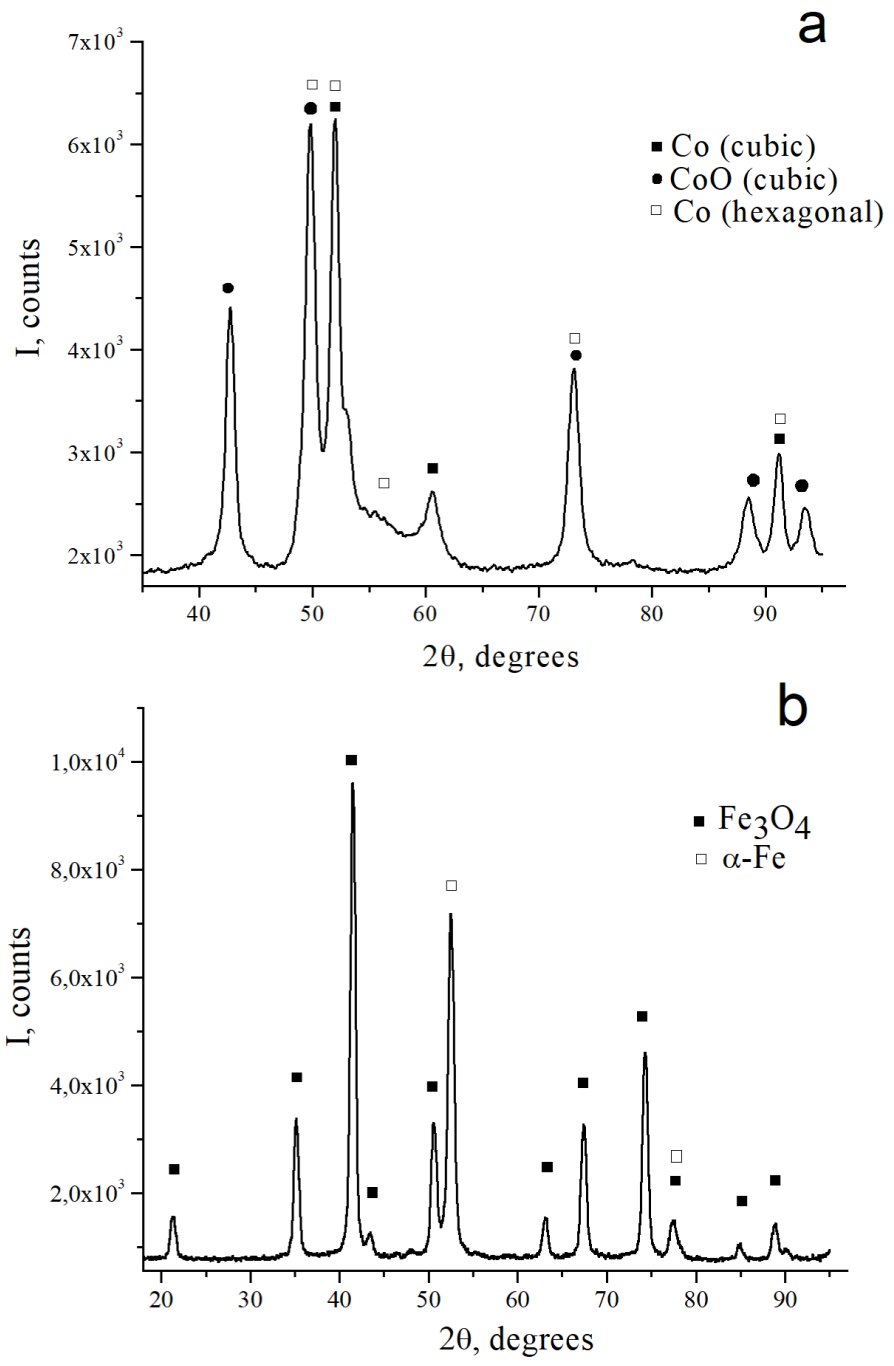

Fig. 4. XRD patterns of $\mathrm{Co}_{93} \mathrm{Fe}_{7}$ (a) and $\mathrm{Co}_{14} \mathrm{Fe}_{86}$ (b) samples.

\section{Conclusions}

A series of inexpensive $\mathrm{Co}-\mathrm{Fe}$ catalysts of $\mathrm{CO}_{2}$ hydrogenation was tested in the atmospheric pressure conditions. A sample with $7 \%$ Fe shows a pronounced catalytic activity and is primarily formed by cubic $\mathrm{Co}(\mathrm{Fe})$ phase, in agreement to $\mathrm{Fe}-\mathrm{Co}$ phase diagram which shows one cubic alloy for this composition. This phase must be considered responsible for the high catalytic activity. Addition of small amount of Fe stabilizes the cubic phase and has an effect on morphology, promoting smaller particle size. Catalysts with high Fe content demonstrate poor activity instead. 


\section{References}

[1] J. Gao, Y. Wang, Y. Ping, D. Xu, G. Xu, F. Gu F. Su, RSC Adv. 2, 2358 (2012).

[2] M. Jacquemin, A. Beuls, P. Ruiz, Catal. Today 157, $462(2010)$.

[3] E. Giglio, A. Lanzini, M. Santarelli, P. Leone, J. Energy Stor. 1, 22 (2015).

[4] E. Giglio, A. Lanzini, M. Santarelli, P. Leone, J. Energy Stor. 2, 64 (2015).

[5] Bin Miao, Su Su Khine Ma, Xin Wang, Haibin Su, Siew Hwa Chan, Catal. Sci. Technol. 6, 4048 (2016).

[6] A. Westermann, B. Azambre, M. Bacariza, I. Graca M. Ribeiro, J. Lopes, C. Henriques, Appl. Catal. B 59, $314(2015)$.

[7] V. Budarin, V. Diyuk, L. Matzui, L. Vovchenko, T. Tsvetkova, M. Zakharenko, J. Therm. Anal. Calorim. 62, 345 (2000).
[8] Y.-G. Chen, K. Tomishige, K. Yokoyama, K. Fujimoto, Appl. Catal. A Gen. 165, 335 (1997).

[9] D.C. Upham, A.R. Derk, S. Sharma, H. Metiu, E.W. McFarland, Catal. Sci. Technol. 3, 1783 (2015).

[10] Chemistry Handbook Vol. 1, Ed. B.P. Nikolskiy, Chemistry, Moscov 1966) (in Russian).

[11] J.J. Gamman, G.J. Millar, G. Rose, J. Drennan, J. Chem. Soc. Faraday Trans. 94, 701 (1998).

[12] W. Wang, S. Wang, X. Ma, J. Gong, Chem. Soc. Rev. 40, 3369 (2011).

[13] I. Ohnuma, H. Enoki, O. Ikeda, R. Kainuma, H. Ohtani, B. Sundman, K. Ishida, Acta Mater. 50, 379 (2002).

[14] W. Wang, Sh. Wang, X. Ma, J. Gong, Chem. Soc. Rev. 40, 3703 (2011). 